\title{
Urban Water Supply Sector Reform in Kathmandu Valley
}

\author{
Dol Prasad Chapagain \\ Singhania University, Rajasthan, India \\ Corresponding email: dpc1279@yahoo.com
}

\begin{abstract}
The sustainable governance of water resources requires that policy makers adapt to changing environmental and socioeconomic context. The efficient management of water resources is vital for its sustainable access and use. Therefore, adequate management practices are needed. Institutional reforms governing the water sector are undergoing remarkable changes and several efforts have been made in this direction for a long time to enhance the water service level. Currently, Kathmandu Upatyaka Khanepani limited (KUKL) is responsible for managing urban water and sanitation service to the Kathamndu Valley. It is the public company registered under the Nepal Government's company Act 2006 and operates under public private partnership (PPP) modality, which is a part of urban water supply sector reforms of Kathamndu Valley. However, the basic requirement of water and sanitation service level has not changed sustainably. This paper focused to understand the institutional structure of the reforms and to examine the roles of institutions involved and stakeholders. This paper attempted to find out the real problem of water supply and why inadequate water service in Kathmandu valley though many institutional changes occurred.

Literatures were reviewed and a descriptive, qualitative design was adopted to generate empirical data. This study finds that urban water supply sector reform of Kathmandu Valley is much closer to the Scott's theory which consists of cognitive, normative and regulative structure and activities that work together provide stability and meaning to social behavior. However, findings are incongruent with this view point. Findings also show that focal problem of water supply is depleting water sources and widening the gap between demand and supply. Additionally, findings show that lack of coordination among stakeholders, weak institutional structure, unstable political scenario, and unplanned urbanization give rise to the problem, leading wider implications to the health of people and national economy. This paper discusses the results of the study and recommends improving the situation.
\end{abstract}

Keywords: institution, reform, institutional theory, stakeholders, vicious cycle, spiral downward, focal problem.

\section{Context}

The management of natural resources receives increasing attention all over the world. The unsustainable exploitation and supply of natural resources endanger the existence and welfare of current and future generations. One of these resources is water, which has increasingly become a locus of concern in several countries. The efficient management of water resources is vital for its sustainable access and use. Therefore, adequate management practices are needed [2].

The institutional reforms governing the water sector are undergoing remarkable changes in many countries around the world. Such changes, which have been observed, especially during the past decade or so, are expected more purposive reform programs than to the normal process of institutional evolution [6]. 
The drinking water supply sector in Nepal has gone through a series of reforms through institutional changes in an effort to make water services accessible to all citizens. An overview of institutional changes in the drinking water sector that occurred is presented in table 1 to provide a background for this paper.

Table 1: Institutional changes for water service provision with time.

\begin{tabular}{|c|c|c|c|c|c|c|c|}
\hline \multirow{2}{*}{ Service area } & \multicolumn{7}{|c|}{ Institutions and period } \\
\hline & \multirow[t]{2}{*}{1891} & \multirow[t]{2}{*}{1929} & 1972 & 1974 & 1984 & 1990 & 2008 onward \\
\hline Rural & & & DWSS & \multicolumn{4}{|c|}{ DWSS } \\
\hline $\begin{array}{l}\text { Urban, inside } \\
\text { Valley }\end{array}$ & $\mathrm{BD}$ & \multicolumn{2}{|c|}{ PG } & WSSB & WSSC & NWSC & KUKL \\
\hline $\begin{array}{l}\text { Urban, outside } \\
\text { Valley }\end{array}$ & & & & $\begin{array}{l}\text { WSSB/ } \\
\text { DWSS }\end{array}$ & $\begin{array}{l}\text { WSSC/ } \\
\text { DWSS }\end{array}$ & $\begin{array}{l}\text { NWSC/ } \\
\text { DWSS }\end{array}$ & NWSC/DWSS \\
\hline \multicolumn{8}{|c|}{$\begin{array}{l}\text { BD -Bir Dhara piped water system, started in } 1891 \text { to manage first drinking water supply in few } \\
\text { selected parts of Kathmandu }\end{array}$} \\
\hline \multicolumn{8}{|c|}{ PG - Pani Goswara, established in 1929 to succeed BD } \\
\hline \multicolumn{8}{|c|}{$\begin{array}{l}\text { DWSS - The Department of Water Supply and Sewerage (DWSS), established in } 1972 \text { to } \\
\text { manage drinking water for urban, semi urban and rural areas throughout the country }\end{array}$} \\
\hline \multicolumn{8}{|c|}{$\begin{array}{l}\text { WSSB - Water Supply \& Sewerage Board (WSSB), established in } 1974 \text { to manage drinking } \\
\text { water in Kathmandu Valley and some urban areas of outside Valley, and remaining urban areas } \\
\text { of outside valley were managed by DWSS }\end{array}$} \\
\hline \multirow{2}{*}{\multicolumn{8}{|c|}{$\begin{array}{l}\text { WSSC - Water Supply \& Sewerage Corporation (WSSC), established in } 1984 \text { to succeed WSSB } \\
\text { NWSC- Nepal Water Supply Corporation (NWSC), established in } 1990 \text { with objective of } \\
\text { improving drinking water supply services in Kathmandu Valley and outside Valley, and to } \\
\text { expand service to the outside urban areas as well. }\end{array}$}} \\
\hline & & & & & & & \\
\hline \multicolumn{8}{|c|}{$\begin{array}{l}\text { KUKL - Kathmandu Upatyaka Khanepani Limited (KUKL), established in } 2008 \text { to manage } \\
\text { drinking water supply and sanitation services to the urban of Kathmandu Valley and separated } \\
\text { from NWSC. }\end{array}$} \\
\hline
\end{tabular}

(Source: DWSS, 2013 \& water diary, 1971-2008)

Following the separation of Kathmandu Valley drinking water supply sector from the Nepal Water Supply Corporation (NWSC), the idea was to Materialize the long awaited Melamchi Water Supply Project and run the urban drinking water supply on a commercial basis. One of the strategies was to introduce PPP model in the urban drinking water supply to achieve a number of objectives [1]. Those were to:

- Improve efficiency in production and distribution through improved operation and maintenance, cost effectiveness and pricing strategy directed by commercial principles

- Increase access to drinking water supply by expanding the supply of safe drinking water

- To ensure sustainability through cost recovery and improved management

- To make provision that poor households have access to safe water

- To relieve the Government of Nepal of the financial burden by accessing private capital. 


\section{Legal Reforms}

In order for the proposed institutional reforms to take effect, legal reforms must first be introduced. The Nepal Water Supply Corporation Act $2^{\text {nd }}$ Amendment (2007), Water Supply Management Board Act, Nepal (2006) and Water Tariff Fixation Commission Act, Nepal (2006) were enacted and gave Water Supply Tariff Fixation Commission (WTFC) power to set tariffs. Furthermore, the KUKL has to follow the Kathmandu Valley Water Supply Management Board and Water Tariff Fixation Commission requirement to regulate itself on drinking water service and quality.

\section{Institutional Reforms}

Donors to the Melamchi Water Supply Project have made conditional a series of institutional reforms to be made to the government agency currently managing drinking water supply to the Valley. Included in the proposed institutional overhaul was the introduction of a foreign, privatesector Management Contractor. To separate the functions of policy formulation, planning, operations and regulation, it was envisaged that NWSC should be separated from Kathmandu Valley and following responsible agencies created:

Kathmandu Valley Water Supply Management Board (KVWSMB). Kathmandu Valley Water Supply Management Board (KVWSMB) is an autonomous government body formed under Water Supply Management Board Act, 2063. The reporting line ministry of the KVWSMB is Ministry of Urban Development (MOUD). KVWSMB is the asset owner of all assets associated with water supply and sewerage system in Kathmandu Valley. It is responsible for developing and overseeing service policies, and providing license to service providers for the operation and management of water supply and sanitation service system in Kathmandu Valley and monitoring the same in order to ensure supply of sufficient drinking water with an acceptable residual pressure head at an affordable price to its consumers [8].

With respect to the water supply sector reforms, the establishment of KVWSMB has given attention to water resource management. The KVWSMB focuses on the water resources, which is the raw material for the water supply sector. Prior to the establishment of KVWSMB, NWSC was collaborating with ministry of physical planning and works for managing the water resources.

Presence of KVWSMB, it has provided the asset to the Kathmandu Upatyaka Khanepani Limited (KUKL) in 2008 by way of a lease agreement for 30 years. Since then water supply and sewerage system of the valley is being operated by KUKL. The KVWSMB is basically working as the asset owner, whose main responsibility is monitoring the works done by KUKL and overall management of the water supply and sewerage system. KUKL pays certain fees against it [3]. Apart from this, the KVWSMB has the responsibility of groundwater management.

Water Tariff Fixation Commission (WTFC). WTFC was formed for the protection of the interests of consumers by providing qualitative and reliable water supply and sanitation service to the consumers at a reasonable price, by fixing the tariff of water supply and sanitation service [9].

WSTFC and KUKL have developed a customer charter, which stipulates the roles and responsibilities of both the customer and the utility. 
The presence of WTFC has increased the number of accountability relationships for KUKL. The accountability to WTFC is primarily through the introduction of performance targets and its role in tariff approval. The independence of WTFC in its functioning reduces the extent of political interference in tariff setting.

Kathmandu Upatyaka Khanepani Limited (KUKL). KUKL is a public company registered under the Nepal Government's Company Act 2006 and operates under the Public Private Partnership (PPP) modality, which was as a part of the urban water supply sector reforms by the government. According to KUKL's Articles of Association, the company has the objective to undertake and manage the water supply and sanitation system of the Kathmandu Valley previously operated by NWSC and to provide a quantitative, qualitative and reliable service to its customers at an affordable price. It is under the oversight of the KVWSMB, 30 years lease and license agreement. To be clear, the KUKL shareholders structure and current institutional arrangements is exhibited in table 2 and figure 1 respectively.

Table 2: Shareholders structure of KUKL

\begin{tabular}{|c|l|c|}
\hline S. No. & Shareholders & Share percentage \\
\hline 1 & Government of Nepal & 30 \\
\hline 2 & Kathmandu Municipality & 30 \\
\hline 3 & Lalitpur Municipality & 10 \\
\hline 4 & Bhaktapur, Madhyapur Thimi \& Kirtipur Municipality & 10 \\
\hline $\mathbf{5}$ & Private Sector Organizations: & \\
\hline & FNCCI & 3 \\
\hline & Lalitpur Chamber of Commerce & 1.5 \\
\hline & Nepal Chamber of Commerce & 9 \\
\hline & Bhaktapur Chamber of Commerce & 1.5 \\
\hline $\mathbf{6}$ & Employees Trust to be paid by GON & $\mathbf{1 0 0}$ \\
\hline & Total & \\
\hline
\end{tabular}

In addition to the services from KUKL, there are other service providers in the Kathmandu urban areas serving those underserved or un-served by KUKL. These service providers, referred to as the Alternative Service Providers (ASP), rely on KUKL sources or their own sources of water for serving their customers. Their activities are basically not regulated in terms of prices and water quality, but currently serve about $15 \%$ of the urban and peri- urban population (World Water Day, 2013). 


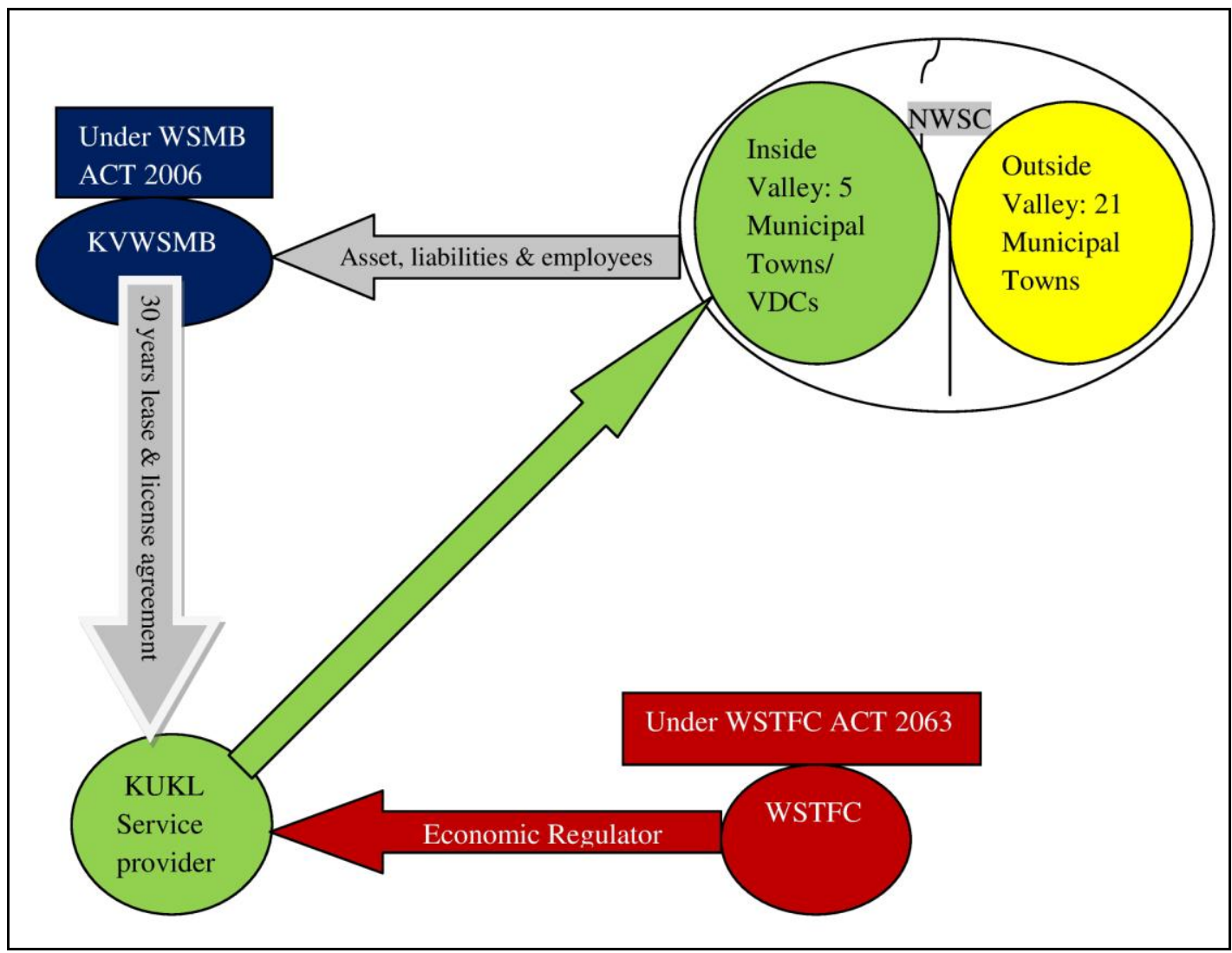

Figure 1: Current institutional arrangements

\section{Objective}

Main objective of this paper is to understand the institutional structure of the Kathmandu urban water supply sector and to examine the roles of institutions involved and stakeholders. Besides, this will outline the water supply status in Kathmandu Valley; determine the focal problem of water supply service and the causes and effects of the problem.

\section{Operational Definition of Terms}

The concept of institution as used in this refers to the actors and stakeholders whose actions and inactions affect urban water supply. Though there are innumerable actors and stakeholders in the water supply sector, key informants of Ministry of Urban Development, KVWSMB, WSTFC, KUKL and sector professionals were canvassed for this study.

\section{Research Procedure}

Attempt was made in exploring the assumption of Kathmandu urban water supply sector reform and roles of institutions involved and stakeholders for existence of water supply sector of Kathmandu Valley. The attempt focused on water supply status, focal problem of water supply service. Related literatures were reviewed and empirical data were collected from the different sources. Data were collected through discussion and depth interviews with key informants of 
Ministry of Urban Development, KVWSMB, WSTFC, KUKL and sector professionals. Finally, a half day experience sharing programme was organized to verify data for assuring reliability.

\section{Data Analysis and Interpretation}

\section{Institutional Structure}

As the institutional arrangements made in Kathmandu urban water supply sector reform, there is diverse institutional spheres that make up society; examining the ways in which individuals are empowered and constrained by shared normative systems and exploring the ways in which symbolic-systems, cultural rules and schemas shape and support social life. In this sense, Kathmandu Valley water supply sector is closed to the Scott's Pillars institutional theory.

There is a general lack of a common definition of institutions within varying definitions are based upon different conceptions of the nature of social reality and order. One definition found to effectively integrate several important elements from other definitions is that of [7]. According to [7] (p.30) institutions "consist of cognitive, normative, and regulative structures and activities that provide stability and meaning to social behavior. Institutions are transported by various carriers-cultures, structures, and routines and they operate at multiple levels of jurisdiction". These elements are the building blocks of institutional structures, and provide the concept of institutions.

\section{Relevance Scott's Pillars of Institutions}

The purpose of this paper is to understand the institutional structure of the Kathmandu urban water supply sector and to examine the roles of institutions involved and stakeholders. Scott opined that institutions consist of cognitive, normative, and regulative structures and activities that provide stability and meaning to social behavior. The cognitive element deals with the shared conceptions that constitute the nature of social reality and the frames through which meaning is made. While the normative aspect defines objectives and the appropriate ways of pursuing values, norms and roles, the regulative pillar constrains and regularizes behavior. It consists of laws and rules supported by sanctions that attempt to influence future behavior and ultimately helps decide how individuals must behave.

Kathmandu water supply sector reform has the relation with the cultural-cognitive, normative and regulative pillars of Scott's theory. This is because the sector has the overall responsibility of producing and distributing drinking water to the urban population in Kathmandu Valley and it must fulfill this role to ensure meaningful social life.

At the cultural-cognitive pillar, the Kathmandu drinking water supply sector has shared beliefs and common logics of action and hence conceives that drinking water must be provided through effective management. Therefore, the sector creates a culture involving actors and institutions such as KVWSMB, WSTFC, KUKL, Private sector and many others to fulfill this concept. While normatively Kathmandu drinking water sector has its roles, vision, mission statement and values in line with producing and distributing safe water to the population to ensure meaningful social life. At the regulative level, it formulates rules, institute technical support \& infrastructure, standards, norms \& monitoring backed by sanctioning power to ensure actors and institutions act in the correct way to provide water. Figure 2 shows how the Scott's pillars relate to the Kathmandu drinking water sector. 


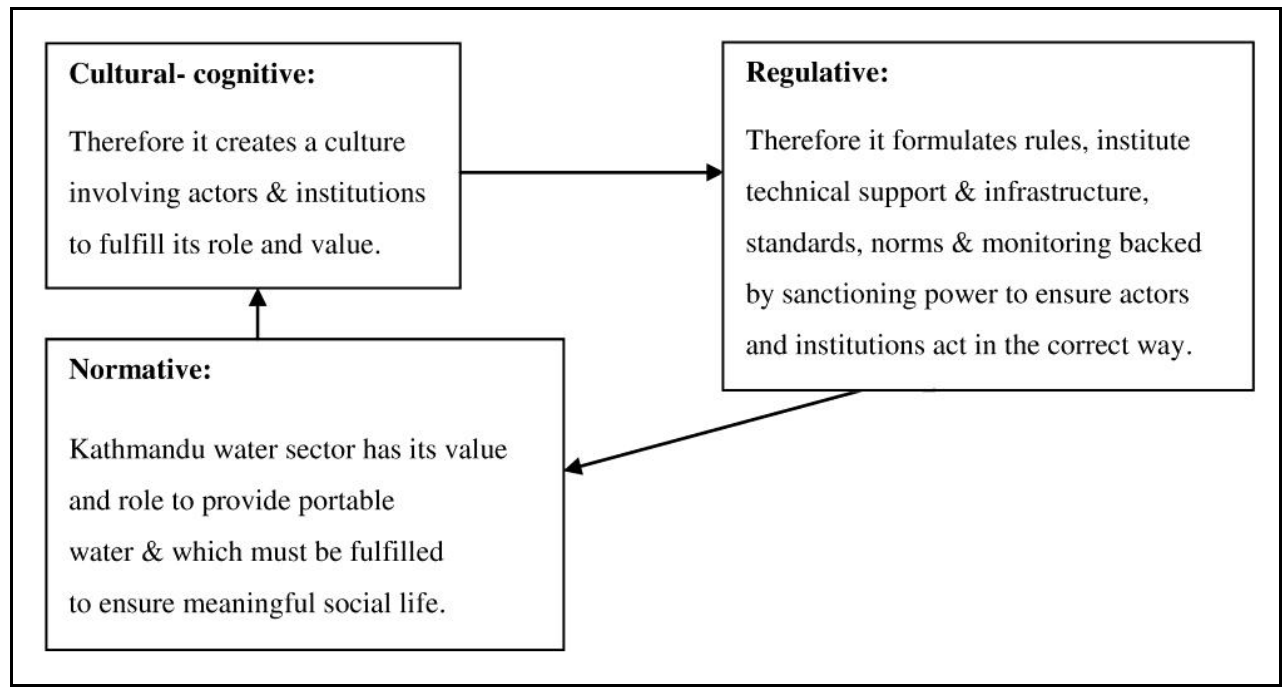

Figure 2: Application of Scott's pillars to the Kathmandu water sector

A further discussion of urban drinking water supply in Kathmandu Valley shows that many actors and institutions are involved and each contributes ideas (manifested in policy formulation) to ensure regular water supply. The Kathmandu drinking water sector using Scott's theory can be likened to human beings in which the various parts (heart, lungs, etc.) function to maintain its existence (see figure 3). In other words, the functions performed for the Kathmandu drinking water sector by its component actors and institutions ensure adequate drinking water supply. The individual actors and institutions roles appear to be independent, but in fact the totality of these roles is a mosaic of patterns which ensure drinking water supply.

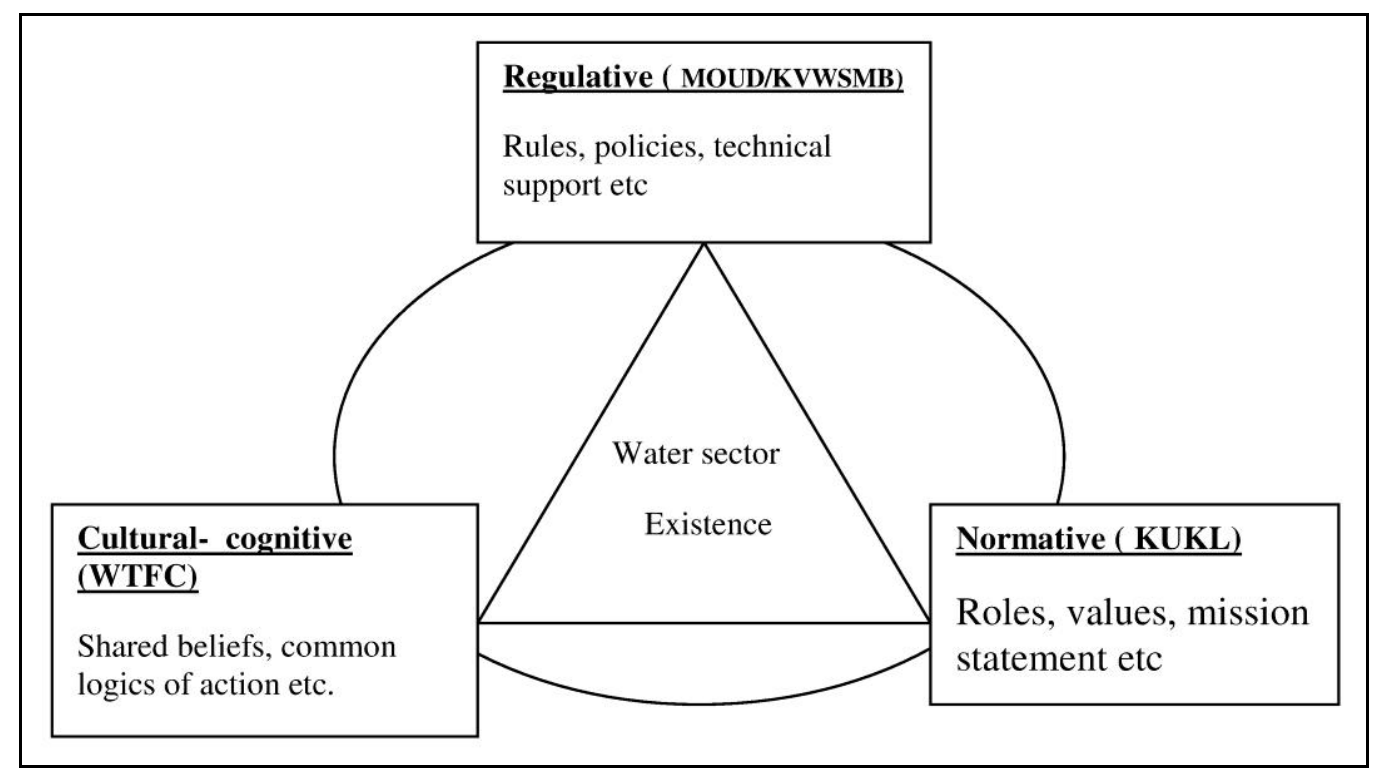

Figure 3: Relationship of Scott's pillars to the Kathmandu urban water sector 


\section{Challenges of Water Supply in the City}

Cities all over the world are facing a range of dynamic regional and global pressures (Figure 4). Due to these pressures, providing safe water supply, basic sanitation and maintaining the environment is likely to be more difficult in the city.

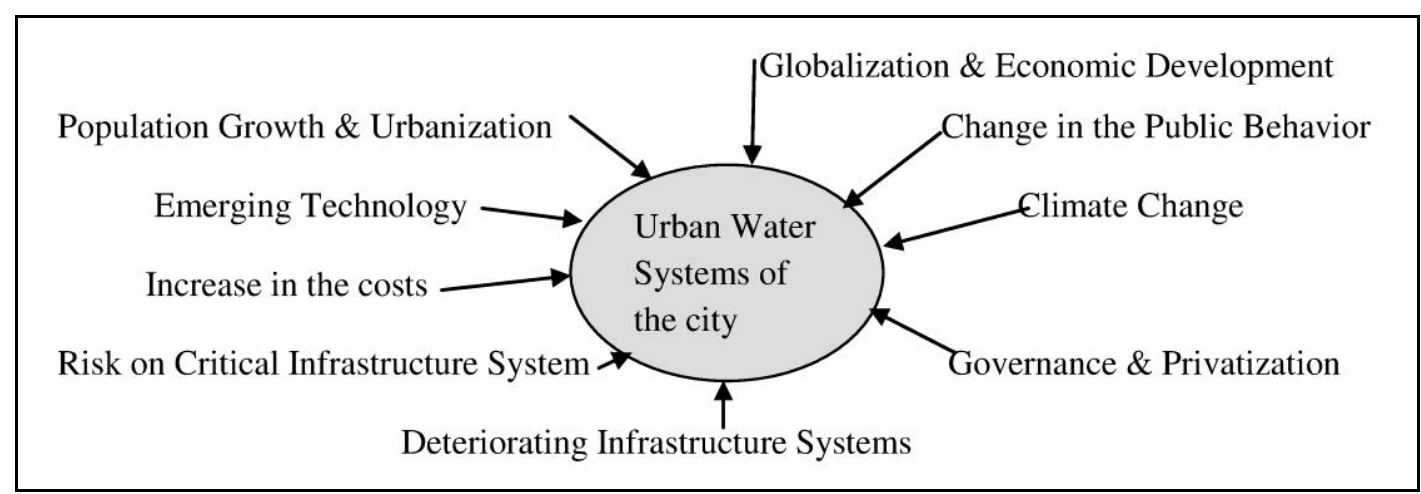

Figure 4: Global change drivers in the city of water supply

(Kalanithy Vairavamoorthy, 2008)

\section{Three of the major pressures are:}

- Climate change: predicted to cause significant changes in precipitation and temperature patterns, affecting the availability of water and quality.

- Population growth and urbanization: leading to a dramatic increase in high-quantity water consumption, while the discharge of insufficiently treated wastewater increases costs for downstream users and has detrimental effects on the aquatic systems.

- Aging and deteriorating water related infrastructure: there is a technological and financial challenge to maintain and upgrade infrastructure in such a way that quality water can continue to be delivered to all sectors and wastewater can be adequately collected and treated.

In order to develop sustainable urban water solution, one must recognize these global change pressures.

\section{Water Supply Scenario}

Kathmandu Valley, an area of 665 square kilometers and home to 2.6 million people is the country's largest urban economy and is critical to Nepal's economic growth. Water is central to the well-being of the population and the key to its productive capacities. However, current water services are grossly inadequate and unreliable causing many people to resort to tankers supplies, bottled water and both deep and shallow wells. Kathmandu Upatayaka Khanepani Limited's unaccounted-for water (UFW) stands at about 50 per cent of total production, the production of water is 139 MLD in wet season and 90 MLD in dry season whereas demand is 350 MLD shown in figure 5.

To be explicit, non scientific and outdated piped water systems do not function efficiently and characterized by low water pressures and frequent breakdowns. Thus, urban water supply and sanitation is in a downward spiral as exhibited in figure 6. 


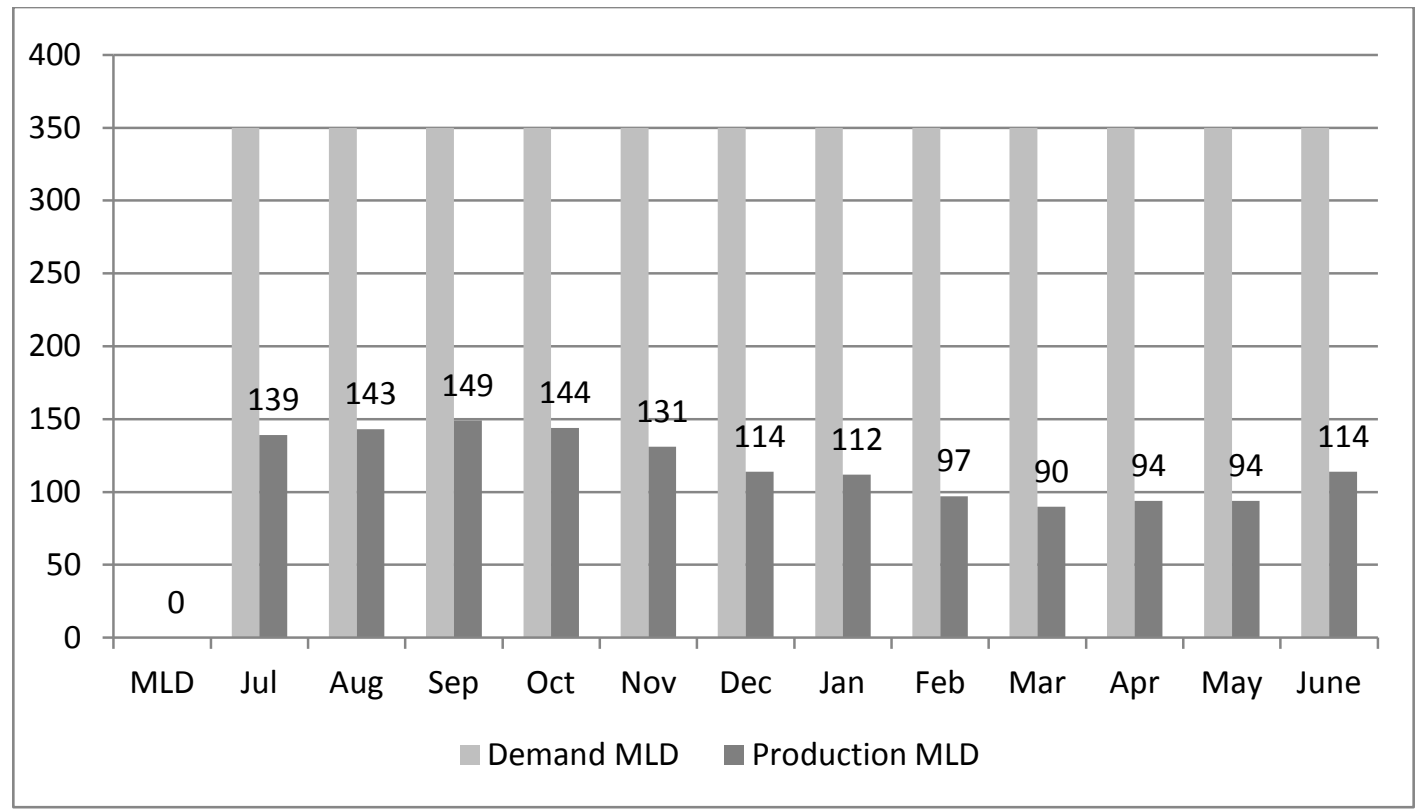

Figure 5: Demand and average daily water production in MLD (2012) (Source: [3])

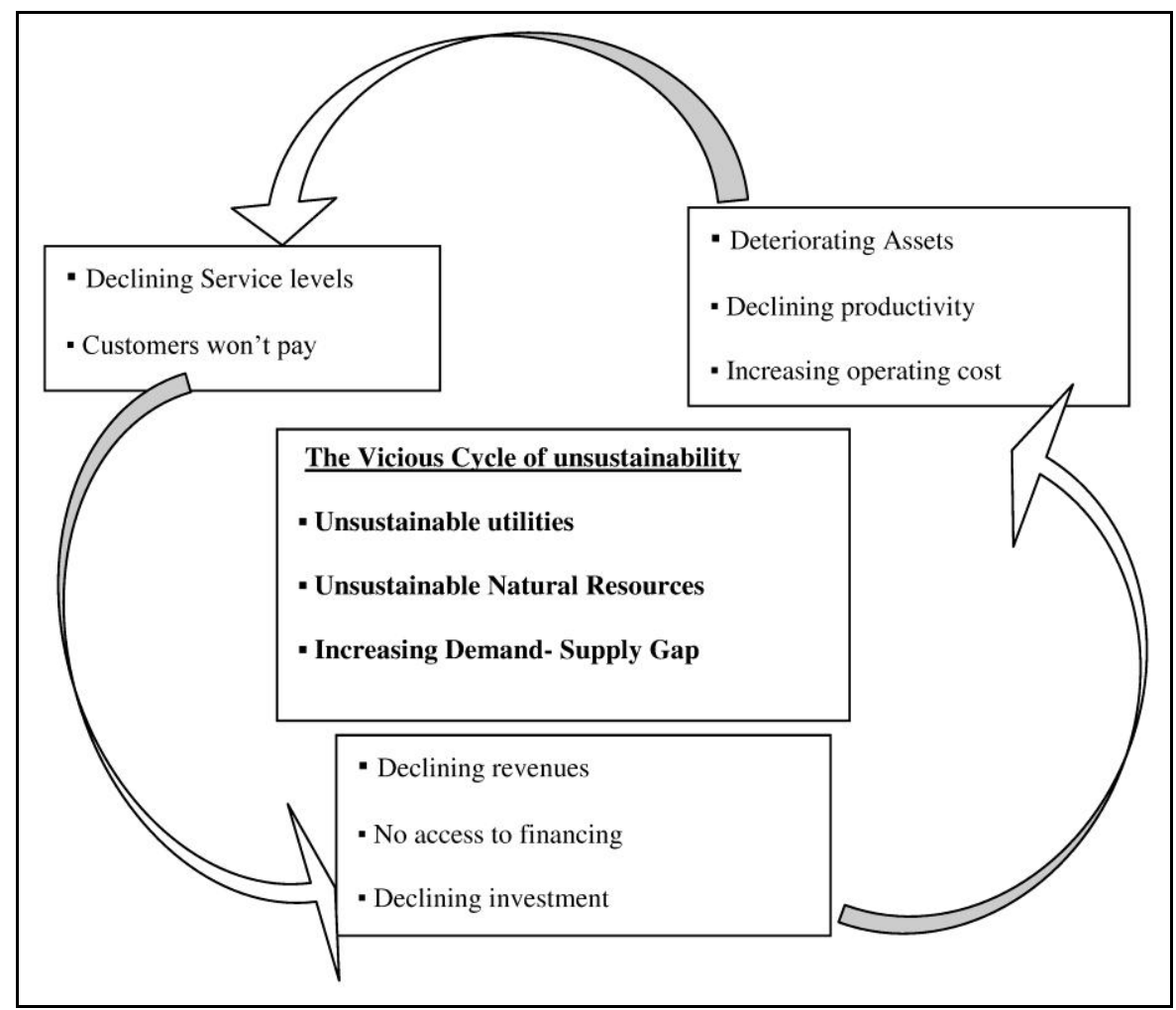

Figure 6: Downward spiral in Water and Sanitation (Source: [5]) 
Due to deteriorating assets, declining productivity has led to increasing operating costs. This, in turn, has led to declining service levels which encourages customers not to pay leading to declining revenues, lesser access to financing and thus lesser investment in the asset. And the downward spiral continues. This leads to a vicious cycle of un-sustainability- unsustainable utilities, depleting natural resources and increasing demand -supply gap. In this situation, Service Providers are in perpetual operational \& financial distress. Service expansion is impossible. This Paradox closely resembles the condition of Water Supply System of Kathmandu Valley.

\section{Problem Tree of Urban Water Supply in Kathmandu Valley}

Main purpose of reforming Kathmandu urban water supply sector was to improve the water and sanitation service level. However, water supply service level in Kathmandu Valley is declining and it has led to a vicious cycle of unsustainable utilities. This paper focused to find out the problem and found that the focal problem is depleting the water resources and widening the gap between demand and supply.

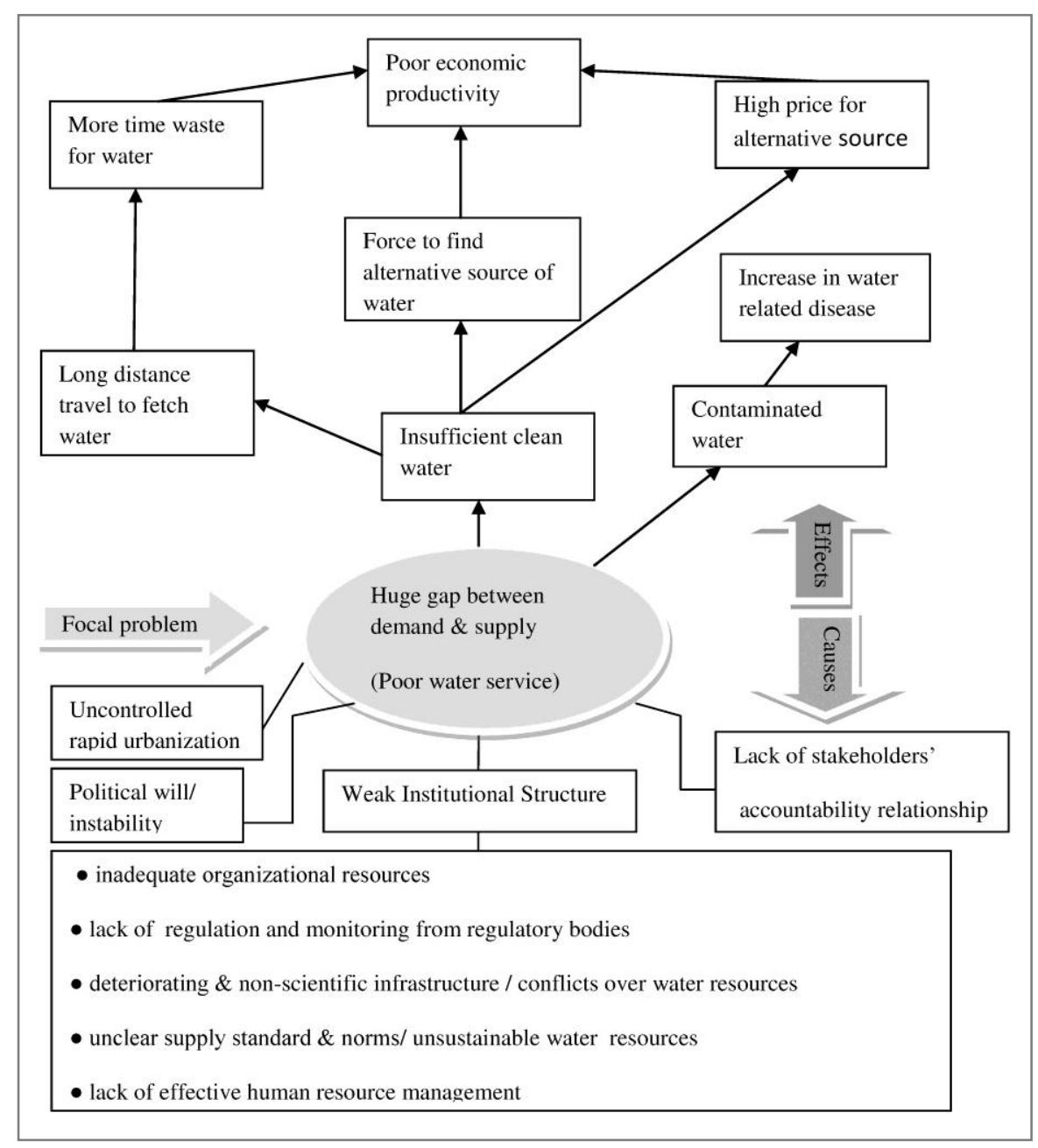

Figure 7: Problem tree showing the causes and effects of water supply 
To be clearer, problem tree is exhibited in Figure 7. The arrow pointing upwards represents the effects of poor water service level in the Kathmandu. They include travelling long distances in search of water, more time waste, high prices for alternative sources of water, users being forced to find alternative sources of water, increase in water related diseases, and insufficient clean water for domestic use, leading to poor economic productivity.

The arrow pointing downwards represents the explanatory variables which gave rise to the poor water service in the Kathmandu. These include: lack of stakeholders' accountability relationship, political will or instability and uncontrolled rapid urbanization. Another cause of the poor water supply is weak institutional structure in terms of inadequate organizational resources, lack of regulation and monitoring from regulatory bodies, deteriorating \& non-scientific infrastructure, unclear supply standard \& norms, unsustainable water resources, lack of effective human resource management and conflicts over water resources. Therefore, this study is conceptualized as shown in Figure 6 in order to provide the framework for approaching the study.

\section{Conclusion}

This study set out the goal of understanding the institutional structure of the Kathmandu urban water supply sector and to examine the roles of institutions involved and stakeholders. Empirically, it was found that the new institutional structure was surrounded with many constraints and findings are incongruent with the view point of Scott's theory. It was also revealed that frequent change of government influenced previous governments' policies and decisions of drinking water supply sector.

Additionally, the findings showed that uncontrolled urbanization exists on a massive scale and strangulates efforts to supply drinking water. Practically, the results obtained from this study enabled us to understand the broader context issues affecting urban water supply. The overall implication of the study is for the actors and institutions of the urban water supply.

\section{Institutions \& Stakeholders}

Water provision is not the mandate of one actor or institution in Kathmandu Valley. It was found that many actors and institutions are involved in the water supply sector. However, the question this study set out to address was why the many actors and institutions, yet inadequate water. One of the answers of this question is lack of stakeholders' accountability relationship for the common goal and there is total lack of interest, collaborating among the actors and institutions which stalled water supply in Kathmandu Valley. Though a clear delineation of roles has been assigned to every actor and institution in the water supply sector, there exist collaborating problems.

Current institutional structure is much closer to the Scott's institutional theory which consists of cultural-cognitive, normative and regulative structures and activities that work together to provide stability and meaning to social behavior. In other words, the actors and institutions in the drinking water supply sector (KUKL, KVWSMB, WSTFC and consumers, etc.) must work together to resolve the water supply problems in Kathmandu Valley. However, findings are incongruent with this view point and there exists massive lacking. Therefore, from Scott's theory, the inadequacy in water supply could be partly explained by lack of stakeholder coordination for common goal. The gaps in the water supply process are in sharp contrast with Scott's theory. 


\section{Political Will}

From the depth interviews and interaction with key informants, it was realized that there is the lack of political will and drinking water sector policies are not being followed. In the event of frequent change of government, policy direction and decisions also change due to partisan concerns. To improve both water related institutions and water service, political will is a must.

\section{Urbanization and Water Supply}

From the problem tree formation of this study, rapid urbanization is one of the explanatory variables that have given rise to the inadequate water supply. It is, therefore, important to investigate the basic details of this phenomenon and how it contributes to inadequate water supply in the Kathmandu Valley

It was noted that rapid and unplanned urbanization particularly in water sources area has contributed to inadequate water supply in the Valley. Government and estate developers should work in collaboration with town and country planning and lands commission to have all lands service or developed before being sold out.

\section{References}

[1] ADB. (2000). Report and Recommendation of the President to the Board of on a Proposed Loan to the Kingdom of Nepal for the Melamchi Water Supply Project, November 2000. RRP: NEP 31624.

[2] Balint, B. E., Forkutsa, I., \& Reis de Freitas, A. C. (2002). Indicators for the Measurement of Institutional Performance Concerning Water Management. Application for Uzbekistan and Ghana.Center for Development Research.

[3] KUKL Annual Report (2010-2012). Kathmandu Upatyaka Khanepani Limited.

[4] Nallathiga, R. (2006). Reforming Water Sector Governance and Institutions for improving efficiency. The case of Mumbai. International Journal of Regulation and Governance, 6(1), 99-133.

[5] Position Paper (2009) on "The Water and Sanitation Sector in India October 2009, Department of Economic Affairs, Ministryof Finance, Government of India.

[6] Saleth, R. M., and Dinar, A. (2005). Water institutional reforms: theory and practice, Journal of water policy, 7, 1-19.

[7] Scott, R. W. (1995). Institutions and Organizations. Newbury Park, CA. Sage Publications.

[8] Water Supply Management Board Act, Nepal (2006).

[9] Water Supply Tariff Fixation Commission Act, Nepal (2006). 